\title{
Lymphoid neoplasms of the urinary tract and male genital organs: a clinicopathological study of 40 cases
}

\author{
Stephanie D Schniederjan ${ }^{1}$ and Adeboye O Osunkoya ${ }^{1,2}$ \\ ${ }^{1}$ Department of Pathology, Emory University School of Medicine, Atlanta, GA, USA and ${ }^{2}$ Department of \\ Urology, Emory University School of Medicine, Atlanta, GA, USA
}

\begin{abstract}
Lymphoid neoplasms of the urinary tract and male genital organs are relatively rare, comprising less than $5 \%$ of all primary extranodal lymphomas; only a handful of small case series and isolated case reports have been published describing their predominant sites and subtypes. We identified $\mathbf{4 0}$ patients with lymphoid neoplasms of the urinary tract and male genital organs. Hematoxylin and eosin slides and immunohistochemical stains were reviewed, and follow-up data were also obtained. Twenty-six of 40 cases (65\%) were primary genitourinary lymphomas. Mean age at diagnosis was 56 years (range 4-86 years). Among renal, bladder, and ureter lymphomas, a male predominance was noted (1.6:1). The subtypes of the lymphoid neoplasms observed were diffuse large B-cell lymphoma (17 cases, 43\%); Burkitt lymphoma, extranodal marginal zone lymphoma, SLL/CLL, and follicular lymphoma (4 cases, or 10\% each); B-cell ALL (2 cases, 5\%); B-cell lymphoma, unclassifiable, with features intermediate between diffuse large B-cell lymphoma and Burkitt lymphoma, mantle cell lymphoma, plasmacytoma, polymorphic post-transplant lymphoproliferative disorder, and peripheral T-cell lymphoma NOS (1 case, or $2.5 \%$ each). In most cases, the genitourinary tract was the site of initial presentation. Genitourinary tract lymphomas most commonly occurred in the kidney. B-cell non-Hodgkin's lymphomas predominated, with diffuse large B-cell lymphoma being the most common subtype in the entire group. Extranodal marginal zone lymphoma was seen only in the kidney, rather than the bladder, where it is typically thought to be more common. Although this study confirms the predominance of diffuse large B-cell lymphoma in extranodal sites, the findings also highlight the variety of lymphomas that may occur in the genitourinary tract. This diversity of subtypes affirms the importance of fully characterizing lymphomas by immunohistochemistry and other modalities, which are indispensable for accurate diagnosis.
\end{abstract}

Modern Pathology (2009) 22, 1057-1065; doi:10.1038/modpathol.2009.65; published online 17 April 2009

Keywords: lymphoid neoplasms; urinary tract; male genital organs

The incidence of lymphoma ranks among the top five malignant neoplasms. ${ }^{1}$ Extranodal lymphomas, however, comprise a minority of cases: approximately $25-40 \%$, depending on the criteria used. ${ }^{2}$ Lymphomas arising in the urinary tract and male genital organs including the kidney, bladder, prostate, testis, ureter/urethra, and penis account for less than $5 \%$ of extranodal lymphomas. However, it is critical for pathologists, urologists, and oncologists to remain cognizant of the possibility of lymphoma arising in these sites, because of the early recognition of these neoplasms. The reasons for this are twofold: first, lymphoid neoplasms are not typically managed surgically, but rather by increasingly

Correspondence: Dr AO Osunkoya, MD, Department of Pathology, Emory University School of Medicine, Room H174, 1364 Clifton Road, NE, Atlanta, GA 30322, USA.

E-mail: adeboye.osunkoya@emoryhealthcare.org

Received 2 March 2009; revised 18 March 2009; accepted 30

March 2009; published online 17 April 2009 sophisticated chemotherapeutic regimens. Second, to aid in accurate classification, fresh tissue may be necessary for analysis by certain modalities, particularly flow cytometry and some molecular genetic studies.

Since the publication of most reviews of genitourinary lymphomas, classification schemes have changed, and new therapeutic modalities have evolved that are predicated on immunophenotypic classification, with rituximab for CD20-positive lymphomas as an example. Therefore, an updated examination of lymphomas occurring in the urinary tract and male genital organs is warranted.

\section{Materials and methods}

Selection of Study Group

We searched our institution's electronic archive of pathology reports from 1986-2008 and identified 40 
cases of lymphoid neoplasms involving the kidney, ureters, bladder, testes, and prostate. Lymphoproliferative malignancies forming tumor masses in the genitourinary tract, such as lymphoblastic lymphoma/leukemia and plasmacytoma, were included. Myeloid sarcomas were not included in this study. Patient age at diagnosis, sex, clinical history, and outcome were recorded using the electronic medical record and the Social Security Death Index. This study was completed following the guidelines of and with approval from the Emory University Institutional Review Board.

\section{Histological and Immunohistochemical Methods}

Hematoxylin and eosin-stained slides and slides stained with various combinations of the following special stains and immunohistochemical stains were retrieved and reviewed (not all stains were performed on every case): myeloperoxidase, nonspecific esterase, chloroacetate esterase, reticulin, Congo red, cytokeratin, placental alkaline phosphatase, S100 protein, smooth muscle actin, desmin, synaptophysin, prostate-specific acid phosphatase, $\alpha$-fetoprotein, carcinoembryonic antigen, CDX2, ALK-1, HHV-8, TdT, cyclin D1, MIB-1, CD3, CD5, CD10, CD20, CD21, CD23, CD30, CD43, CD45, CD45ro, CD68, CD79a, CD138, kappa, and lambda light chains. In certain cases, additional immunostains (CD20, CD5, cyclin D1) were performed to clarify the tumor immunophenotype. Review of morphology and immunoprofile permitted re-classification of older cases $(n=6)$ into currently accepted diagnostic categories.

\section{Flow Cytometric, Cytogenetic, and Molecular Characterization}

Fresh tissue was procured for flow cytometric immunophenotyping (FCI) in 10 of 40 cases. FCI identified nine of these cases as B-cell lymphomas, while the tenth case was characterized as a plasma cell neoplasm. Fresh tissue was sent for karyotyping in one case. Molecular studies for IgH, T-cell receptor, and/or BCL-2 gene rearrangements were done in three cases.

\section{Results}

Forty cases of lymphoma and plasmacytoma involving the urinary tract and male genital organs diagnosed on biopsy or resection were identified at our institution. Twenty-six of 40 cases (65\%) were primary genitourinary lymphomas (Table 1). Mean age at diagnosis was 56 years (range 4-86 years). Among renal, bladder, and ureter lymphomas, a male predominance was noted (1.6:1). The lymphoma subtypes observed were diffuse large B-cell lymphoma (17 cases, 43\%); Burkitt lymphoma, extranodal marginal zone lymphoma, SLL/CLL, and follicular lymphoma (4 cases, or $10 \%$ each); Bcell ALL (2 cases, 5\%); B-cell lymphoma, unclassifiable, with features intermediate between diffuse large B-cell lymphoma and Burkitt lymphoma, mantle cell lymphoma, plasmacytoma, polymorphic post-transplant lymphoproliferative disorder, and peripheral T-cell lymphoma NOS (1 case, or $2.5 \%$ each).

The kidney (15 cases, 37.5\%) was the most common site of disease. Other affected sites included testis (9 cases, $22.5 \%$ ), prostate (8 cases, $20 \%$ ), bladder (5 cases, $12.5 \%$ ), penis ( 2 cases, $5 \%$ ), and ureter (1 case, $2.5 \%$ ).

The presenting symptoms varied with site of involvement, and included palpable masses, renal insufficiency, hematuria, abdominopelvic pain, and voiding difficulty. Associations with other diseases - neoplastic, inflammatory, or infectious - occurred in some cases, but were uncommon overall (Table 2).

Of 16 renal and ureteral lymphoid neoplasms, 4 were diagnosed on nephrectomy specimens, others on needle core biopsies. (Figures 1a to 2) In two of these cases, renal cell carcinoma was suspected based on CT imaging characteristics. A third case occurred in a renal allograft with a history of posttransplant lymphoproliferative disorder, which had progressed to polymorphic post-transplant lymphoproliferative disorder by the time of nephrectomy. The lymphoma predominantly involved the proximal ureter and periureteral/perinephric fat. The fourth case occurred in a kidney that was resected for a 17-cm myelolipoma. Atypical nodular lymphoid aggregates were seen within the myelolipoma that co-expressed CD20, BCL-2, CD23, and CD43 and was negative for CD5, CD10; molecular studies revealed the presence of a clonally rearranged immunoglobulin heavy chain gene. The findings were thought to be diagnostic of a low-grade B-cell lymphoma, most likely extranodal marginal zone lymphoma. (Figure 3a and b).

In addition to non-Hodgkin's B-cell lymphomas, two pediatric cases of B-cell lymphoblastic lymphoma occurred in the testis, as well as an extraosseous plasmacytoma (Figure 4a-c). Diffuse large B-cell lymphoma predominated among testicular nonHodgkin's lymphomas, with one case of secondary involvement by Burkitt lymphoma. Predictably, the lymphomas, where documented, presented with palpable masses .

Prostatic lymphomas presented with hematuria, voiding symptoms, and/or urinary tract obstruction. One case occurred in a patient with a history of 'granulomatous prostatitis,' and one patient subsequently developed prostatic adenocarcinoma that ultimately metastasized, resulting in death 8 years after the diagnosis of lymphoma. (Figure 5a-c).

Four of five bladder lymphomas were primary, and diffuse large B-cell lymphoma was the most common subtype identified. The two other lymphoma subtypes were mantle cell lymphoma and 
Table 1 Summary of lymphoma sites, subtypes, demographics, and outcome

\begin{tabular}{|c|c|c|c|c|c|}
\hline Site & Diagnosis & Age & Sex & Primary/secondary & Outcome \\
\hline \multirow[t]{15}{*}{ Kidney $(n=15)$} & DLBCL & 33 & $\mathrm{M}$ & Secondary & NED 4-year follow-up \\
\hline & DLBCL & 73 & $\mathrm{~F}$ & Secondary & DWD 1 month later \\
\hline & DLBCL & 30 & $\mathrm{M}$ & Primary & DWD 23 months later \\
\hline & PTLD & 68 & $\mathrm{~F}$ & Secondary & DWD 4 months later \\
\hline & EMZL (MALT) & 54 & $\mathrm{~F}$ & Primary & NED 2-year follow-up \\
\hline & EMZL (MALT) & 65 & $\mathrm{M}$ & Primary & No follow-up \\
\hline & EMZL (MALT) & 75 & $\mathrm{M}$ & Primary & No follow-up \\
\hline & EMZL (MALT) & 50 & $\mathrm{~F}$ & Primary & NED 2-vear follow-up \\
\hline & BL & 4 & $\mathrm{~F}$ & Secondary & NED 6-year follow-up \\
\hline & $\mathrm{BL}$ & 49 & $\mathrm{~F}$ & Primary & DWD 15 months later \\
\hline & $\mathrm{BL}$ & 42 & $\mathrm{M}$ & Primary & DWD 4 months later \\
\hline & FL & 79 & $\mathrm{~F}$ & Secondary & DWD 9 years later \\
\hline & FL & 72 & $\mathrm{M}$ & Secondary & DWD 1 month later \\
\hline & SLL & 45 & $\mathrm{M}$ & Secondary & DWD 5 years later \\
\hline & BCLU & 68 & $\mathrm{~F}$ & Secondary & DWD 2 months later \\
\hline \multirow[t]{5}{*}{ Bladder $(n=5)$} & DLBCL & 44 & $\mathrm{~F}$ & Primary & NED 2.5 years later \\
\hline & DLBCL & 71 & $\mathrm{M}$ & Primary & D 5 months later \\
\hline & DLBCL & 54 & $\mathrm{M}$ & Primary & No follow-up \\
\hline & FL & 80 & $\mathrm{M}$ & Primary & No follow-up \\
\hline & MCL & 69 & $\mathrm{M}$ & Secondary & D 3 months later \\
\hline \multirow[t]{9}{*}{ Testis $(n=9)$} & $\mathrm{BL}$ & 27 & $\mathrm{M}$ & Primary & DWD 10 months later \\
\hline & DLBCL & 86 & M & Primary & DWD 3 years 7 months later \\
\hline & DLBCL & 65 & $\mathrm{M}$ & Primary & NED 1-year follow-up \\
\hline & DLBCL & 33 & $\mathrm{M}$ & Primary & No follow-up \\
\hline & DLBCL & 69 & $\mathrm{M}$ & Primary & No follow-up \\
\hline & DLBCL & 56 & $\mathrm{M}$ & Primary & NED 10-year follow-up \\
\hline & PLASMACYTOMA & 46 & $\mathrm{M}$ & Unknown & No follow up \\
\hline & PRE-B ALL & 16 & $\mathrm{M}$ & Primary & NED 12-year follow up \\
\hline & PRE-B ALL & 8 & $\mathrm{M}$ & Primary & DWD 3.5 years \\
\hline \multirow{9}{*}{ Prostate $(n=8)$} & SLL/CLL & 76 & $\mathrm{M}$ & Primary & DWD 3 years later \\
\hline & DLBCL & 64 & $\mathrm{M}$ & Primary & DND 19 years later \\
\hline & DLBCL & 85 & $\mathrm{M}$ & Primary & DWD 1 months later \\
\hline & DLBCL & 62 & $\mathrm{M}$ & Secondary & DWD 2.5 years later \\
\hline & DLBCL & 38 & $\mathrm{M}$ & Primary & No follow up \\
\hline & FL & 75 & M & Primary & No follow up \\
\hline & SLL/CLL & 70 & $\mathrm{M}$ & Secondary & No follow up \\
\hline & SLL/CLL & 65 & $\mathrm{M}$ & Secondary & AWD 1 year later \\
\hline & SLL/CLL & 76 & $\mathrm{M}$ & Secondary & DWD 3 years later \\
\hline \multirow[t]{2}{*}{ Penis $(n=2)$} & TCL & 72 & $\mathrm{M}$ & Primary & DWD 2.5 months later \\
\hline & DLBCL & 69 & $\mathrm{M}$ & Secondary & DWD 6 months later \\
\hline Ureter $(n=1)$ & DLBCL & 28 & $\mathrm{M}$ & Primary & DWD 2.5 years later \\
\hline
\end{tabular}

ALL, acute lymphoblastic lymphoma; AWD, alive with disease; BCLU; B-cell lymphoma, unclassifiable, with features intermediate between diffuse large B-cell lymphoma and Burkitt lymphoma; BL, Burkitt lymphoma; D, died (disease status unknown); DLBCL, diffuse large B-cell lymphoma; DND, died with no disease; DWD, died with disease; FL, follicular lymphoma; EMZL, extranodal marginal zone lymphoma; MALT, mucosa-associated lymphoid tissue lymphoma; MCL, mantle cell lymphoma; NED, no evidence of disease; PTLD, post-transplant lymphoproliferative disorder; SLL, small lymphocytic lymphoma; TCL, primary cutaneous peripheral T-cell lymphoma.

Table 2 Clinical data for most common lymphoma subtypes

\begin{tabular}{|c|c|c|c|c|c|}
\hline & $D L B C L$ & $B L$ & $E M Z L(M A L T)$ & $F L$ & $S L L$ \\
\hline Affected sites $(n)$ & $\begin{array}{l}\text { Testis (5) } \\
\text { Kidney (3) } \\
\text { Prostate (4) } \\
\text { Bladder (3) } \\
\text { Ureter (1) } \\
\text { Penis (1) }\end{array}$ & Kidney (3), testis (1) & Kidney (4) & $\begin{array}{l}\text { Kidney (2), bladder } \\
(1), \text { prostate (1) }\end{array}$ & $\begin{array}{l}\text { Prostate (3) } \\
\text { Kidney (1) }\end{array}$ \\
\hline Primary extranodal $(n, \%)$ & $12,71 \%$ & $3,60 \%$ & $4,100 \%$ & $4,100 \%$ & $1,25 \%$ \\
\hline Disease associations & & HIV & $\begin{array}{l}\text { Myelolipoma; } \\
\text { FSGS; VWD }\end{array}$ & None & $\begin{array}{l}\text { Renal disease, } \\
\text { acute myeloid } \\
\text { leukemia }\end{array}$ \\
\hline $\begin{array}{l}\text { Average age at diagnosis } \\
\text { (range) }\end{array}$ & 57 years $(28-86)$ & 30 years $(4-49)$ & 61 years $(50-75)$ & 77 years $(72-80)$ & 64 years $(45-76)$ \\
\hline Total $(n, \%)$ & $17,43 \%$ & $4,10 \%$ & $4,10 \%$ & $4,10 \%$ & $4,10 \%$ \\
\hline
\end{tabular}

BL, Burkitt lymphoma; DLBCL, diffuse large B-cell lymphoma; FL, follicular lymphoma; FSGS, focal segmental glomerulosclerosis; HIV, human immunodeficiency virus; EMZL, extranodal marginal zone lymphoma; MALT, mucosa-associated lymphoid tissue lymphoma; SLL, small lymphocytic lymphoma; VWD, von Willebrand disease. 
1060
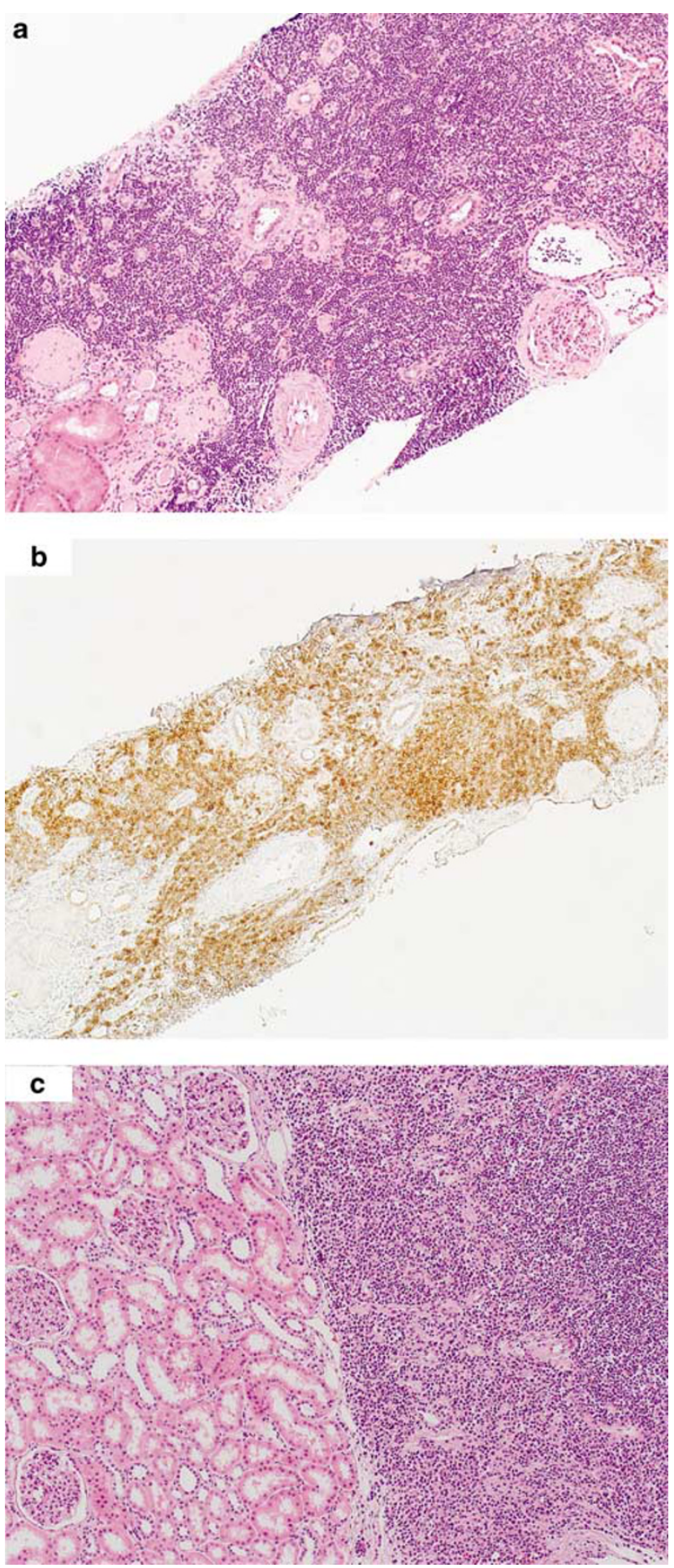

Figure 1 (a) Kidney biopsy showing diffuse large B-cell lymphoma. (b) Kidney biopsy with CD-20 immunoexpression in tumor cells. Corresponds to (a). (c) Nephrectomy specimen with extranodal marginal zone (MALT lymphoma) and adjacent uninvolved renal parenchyma.

follicular lymphoma; extranodal marginal zone lymphoma was not identified. Review of histological slides, particularly from the era pre-dating the disease category of extranodal marginal zone

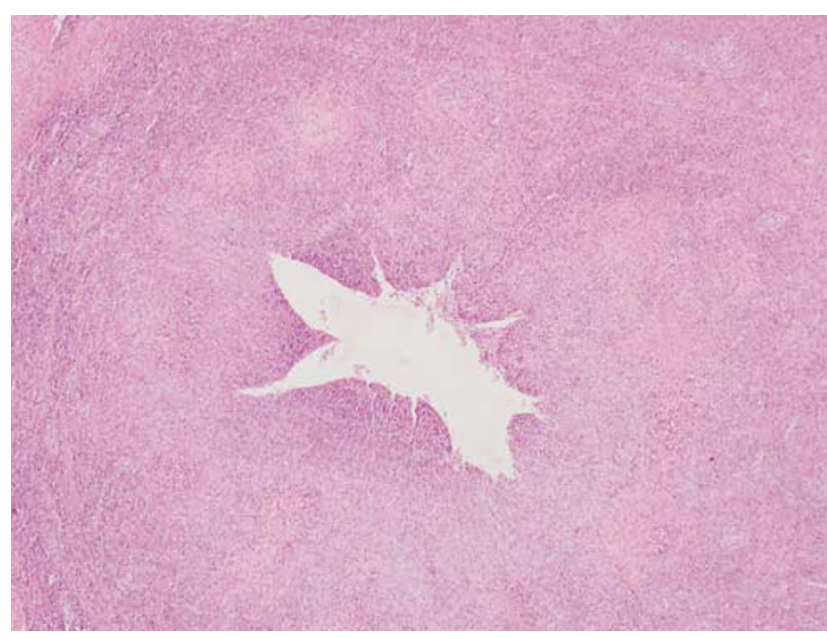

Figure 2 Ureter with diffuse large B-cell lymphoma involving the entire wall and undermining the urothelium.

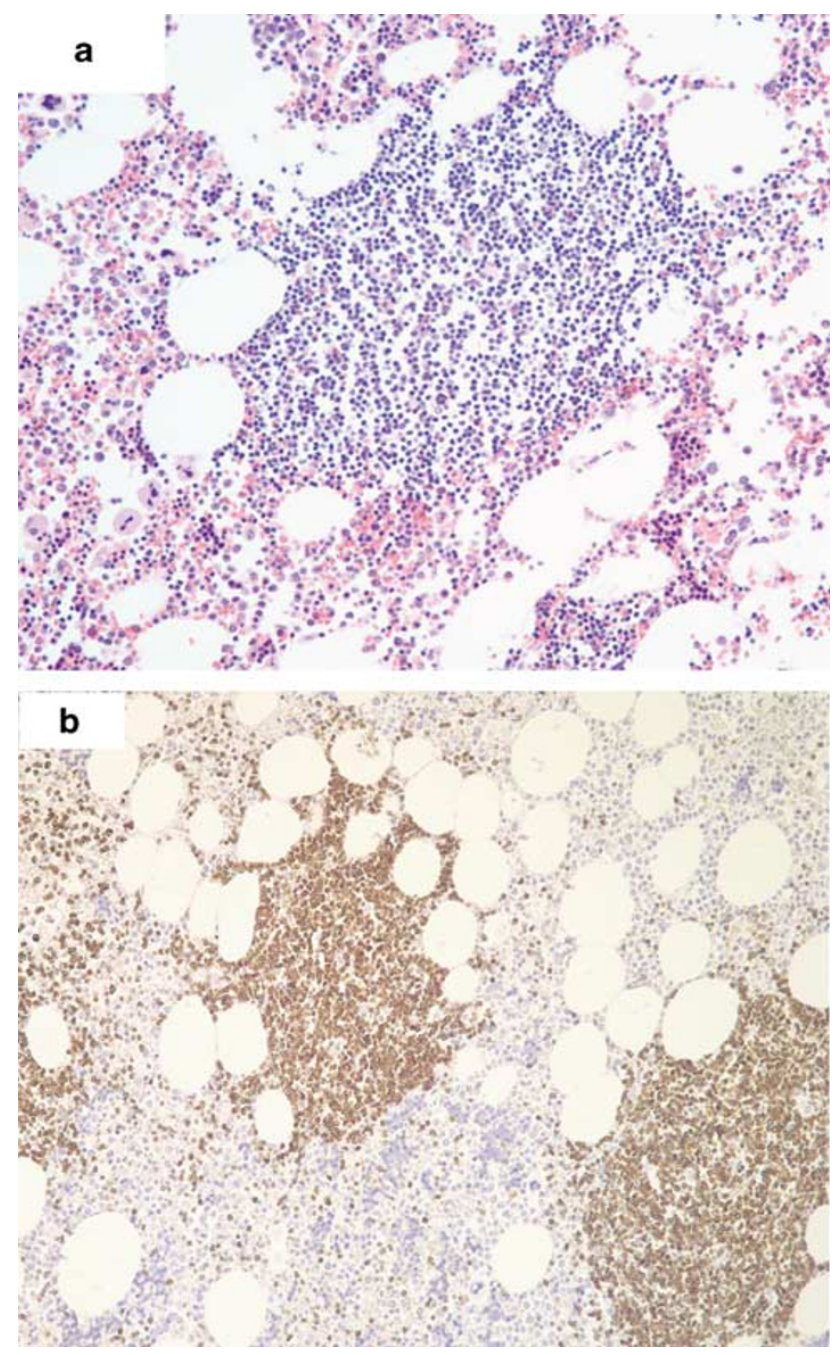

Figure 3 (a) Low grade B-cell lymphoma arising in myelolipoma. (b) Corresponding focus with BCL-2 immunohistochemical stain.

lymphoma, confirmed the diagnoses. At least two of the cases were documented to have presented with hematuria, initially raising the clinical suspicion of 

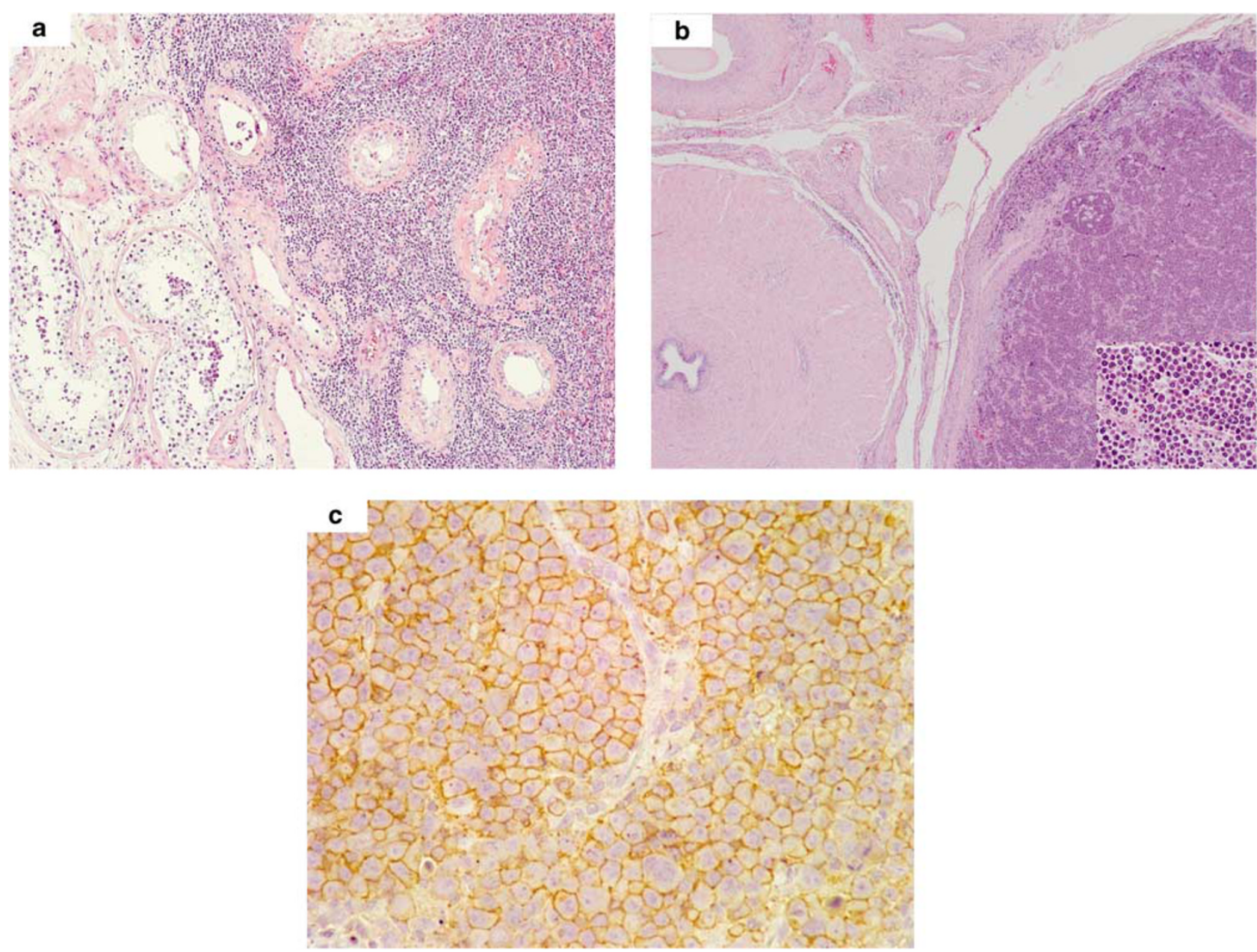

Figure 4 (a) Testis with diffuse large B-cell lymphoma. Note normal spermatogenesis in tubules on the left and maturation arrest with peritubular fibrosis in the tubules entrapped within the tumor. (b) Testis and adjacent spermatic cord, almost completely replaced by plasmacytoma. (c) Plasmacytoma with positive expression of CD-138.

urinary tract infection or urothelial cell carcinoma. Outcome in two cases is unknown; two patients died within 6 months with unknown disease status, and one is alive 2.5 years after diagnosis with no evidence of recurrent diffuse large B-cell lymphoma. (Figure 6a and b) The two lymphomas involving the penis were primary cutaneous peripheral T-cell lymphoma and primary diffuse large B-cell lymphoma, leg type.

In two cases, two other genitourinary sites were subsequently involved. In one case, the patient had a testicular lymphoma and 2 years later developed penile involvement. In the second case, the patient presented with difficulty in urinating and underwent a transurethral resection of prostate that included portions of bladder tissue. Both bladder and prostate were simultaneously involved, but the bulk of tumor appeared to be in the prostate.

\section{Discussion}

Lymphomas arising in the genitourinary tract though relatively uncommon are important to recognize from both the diagnostic and therapeutic standpoint. In accordance with the findings of other studies, nearly all cases of the genitourinary hematolymphoid neoplasms were B-cell non-Hodgkin's lymphomas. ${ }^{3-7}$ Most cases in our series involved the kidney and testis; somewhat surprisingly, there were more lymphomas identified within the prostate than in the bladder. This most likely reflects the increased relative frequency of prostate biopsies rather than any increased propensity for lymphomagenesis. Moreover, half of all prostate cases were secondary, while $80 \%$ of bladder cases were primary.

The determination of primary versus secondary involvement of extranodal sites by lymphoma continues to be problematic. For this study, the criteria proposed by Krol et $a l^{2}$ were used, which dictate that any lymphoma with initial presentation at an extranodal site should be considered extranodal, even if disseminated disease is discovered, in cases where the extranodal component is clinically dominant. The reason for adopting these criteria is that when extranodal lymphoma is defined as lymphoma confined to an extranodal site, this 

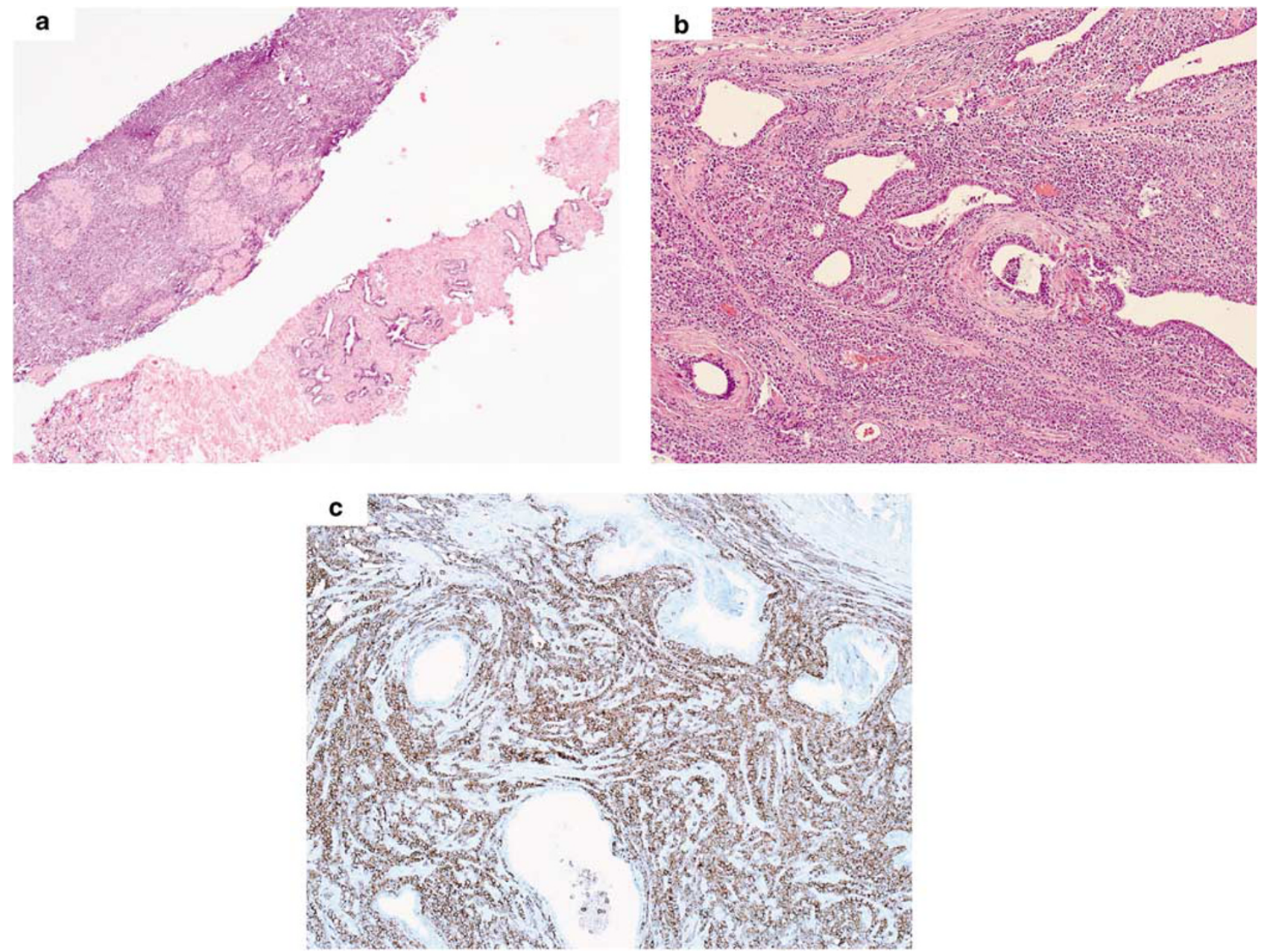

Figure 5 (a) Prostate needle core biopsies with atrophic glands on the inferior core and extensive diffuse large B-cell lymphoma involving the superior core. (b) TURP specimen with CLL/SLL involving the prostate. (c) CD-5 immunoexpression in the monomorphic tumor cells. Corresponds to focus in (b).
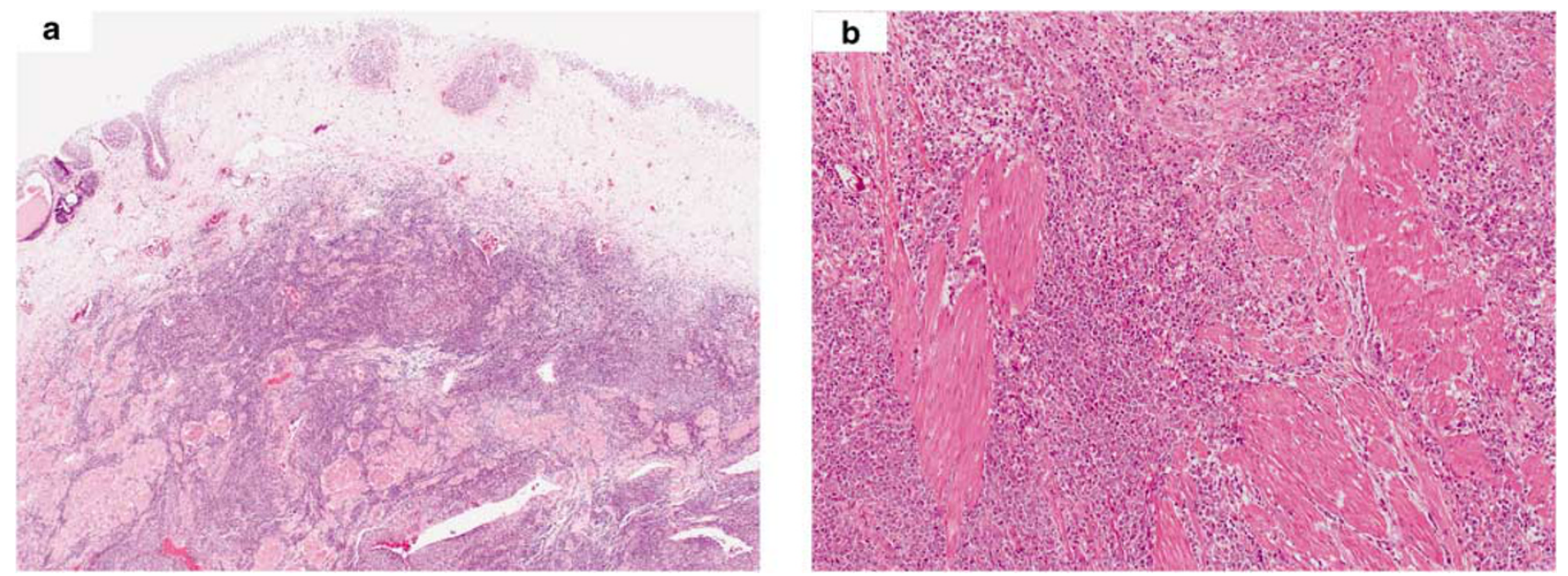

Figure 6 (a) Bladder with diffuse large B-cell lymphoma involving the lamina propria and muscularis propria. (b) Bladder with diffuse large B-cell lymphoma involving the muscularis propria.

selects for low-stage disease; assessments of relative prognosis and other clinical factors then become biased.
In the absence of pre-existing lymphoid tissue, such as may be found associated with urothelial submucosa, it is unclear how the primary genitour- 
inary lymphomas arise. Hematogenous dissemination or direct extension from another occult site of disease may occur. ${ }^{8}$ An underlying, clinically silent inflammatory, or infectious process that undergoes transformation to lymphoma - analogous to what appears to occur in extranodal marginal zone lymphoma arising in the setting of gastric $H$. pylori infection - might represent a second possible explanation.

In our series, the kidney (15 cases, $37.5 \%$ ) was the most common site of genitourinary tract lymphoma. Renal lymphomas may be unilateral or bilateral and typically occurs in middle aged to elderly adults. ${ }^{6,9,10}$ Clinical presentation as in our cases are nonspecific and includes weight loss, flank pain, hematuria, renal failure, loss of appetite, and malaise. Similar to renal cell carcinomas, lymphomas may also be detected incidentally when patients are being worked up radiologically for other reasons. The diagnosis can be made initially by biopsy. ${ }^{11-13}$ Radiologically, multi-detector row CT is one of the imaging modalities of choice for the evaluation of patients with suspected renal lymphoma. This modality not only depicts the renal lesions, but also aids in the identification of extrarenal extension to adjacent anatomic structures and thus can determine the systemic spread of the disease. ${ }^{14}$ Both clinically and pathologically, they can be mistaken for carcinomas of the kidney. In the series by Ferry et $a l,{ }^{6}$ the majority of patients had unilateral disease and B-cell lineage tumors. Four of their 11 patients $(36 \%)$ died of disease within 2 years of presentation. Though diffuse large B-cell lymphoma, follicular lymphoma, and Burkitt lymphoma have been well described in the kidney, primary mucosa-associated lymphoid tissue (MALT) lymphoma of the kidney is another important category in this organ. ${ }^{15,16}$ MALT lymphoma of the kidney can also be the result of systemic involvement, and 3 of the 10 cases $(30 \%)$ in the series by Garcia et $a l^{15}$ had one or more extrarenal sites involved by MALT lymphoma including ocular adnexa 8 years before the diagnosis of kidney involvement, bone marrow, salivary gland, cervical lymph node, and soft tissue.

Testicular lymphomas, though rare, are one of the more common lymphomas involving the genitourinary tract. The most common known subtype in the testis is diffuse large B-cell lymphoma. ${ }^{7}$ In our series, over $50 \%$ of cases were diffuse large B-cell lymphoma. The primary testicular lymphoma typically presents as a palpable testicular mass. It has been observed that the mean age of patients with PTL seems to have shifted in recent years to a relatively younger age group. ${ }^{3}$ This was also shown in our series with the average age in our study being 45 years (range 8-86 years). One of the factors that may be responsible for this phenomenon is the increased incidence of HIV/AIDS in the younger population of patients with testicular lymphoma. ${ }^{17}$
Misdiagnosis of testicular lymphomas as germ cell tumors especially seminoma is not uncommon, and it is critical to make this distinction because of therapeutic implications. Testicular lymphomas are typically characterized by obliteration of the testicular parenchyma in the involved areas by solid sheets of neoplastic lymphoid cells. Splaying of seminiferous tubules by irregular aggregates, clusters, and cords of tumor cells are another characteristic finding in most cases. Infiltration of seminiferous tubules is a rare finding. Microscopic invasion of adjacent structures, including epididymis, and paratesticular tissue occurs in advanced cases. Intratubular germ cell neoplasia was not identified in any case in our series as documented by others. ${ }^{3,18}$ The prognosis of testicular lymphoma is typically dismal and management of patients with testicular lymphoma presents several daunting challenges; thus, an aggressive therapeutic approach is typically warranted. ${ }^{17,19,20}$

Lymphomas involving of the prostate are rare and account for less than $0.1 \%$ of newly diagnosed lymphomas. Some authors have earlier challenged the existence of primary extranodal prostatic lymphoma due to the paucity of lymphoid tissue in normal prostate gland. The recognition of the presence of occasional rudimentary lymphoid nodules, cases of extramedullary hematopoiesis within the prostate, and documented cases of lymphoma limited to the prostate without pelvic or retroperitoneal lymph node involvement have shown that primary prostatic lymphomas exist. ${ }^{5}$ Most primary lymphomas of the prostate are non-Hodgkin's lymphomas and are predominantly of B-cell lineage. In our series, DLBCL was the most common subtype, followed by SLL/CLL and follicular lymphoma, respectively. Other authors have reported cases with primary extranodal MALT and mantlecell lymphoma of the prostate. ${ }^{21,22}$ Most of the patients in our series presented with obstructive symptoms, as have been earlier reported in the literature. ${ }^{23,24}$ Some patients are, however, asymptomatic and could be diagnosed following an abnormal digital examination with subsequent biopsy. ${ }^{25}$ Prostatic lymphomas have a poor prognosis and most of our patients with follow-up died within 3 years of diagnosis. Some studies have shown that prostatectomy as monotherapy may not be the most effective approach to treatment, but prognosis may be improved with adjuvant chemoradiation therapy. ${ }^{5,26}$

Lymphomas of the bladder are also relatively uncommon and patients may present with hematuria as documented in two patients in our series. Patients have also been known to present with urinary obstruction. ${ }^{23}$ The initial clinical impression may thus be urothelial carcinoma or urinary tract infection. There is no definite sex predilection, though some authors have cited a female predominance in their series. ${ }^{27-29}$ As described earlier by others, the common subtypes in our series were 
diffuse large B-cell lymphoma, mantle cell lymphoma, and follicular lymphoma. ${ }^{4,28,29}$ Though a wellknown subtype of lymphoma in the bladder, extranodal marginal zone lymphoma was not present in our series most likely due to the relatively small number of lymphomas with bladder involvement in this study. ${ }^{29-32}$ The best therapeutic approach for bladder lymphomas remains somewhat controversial. Although management options include chemotherapy, radiation, and surgery, chemotherapy is currently favored because it also treats undetectable early systemic disease. ${ }^{28}$

Lymphomas involving the penis are very rare and have only been reported in case reports. ${ }^{33-35}$ Although most lymphomas reported at this site are seen in adults, there has been a case report of primary penile lymphoma in a 4-year-old boy who presented with a painless penile mass. ${ }^{35}$ Penile lymphomas are typically of the B-cell lineage with diffuse large B-cell lymphoma being the most common. Our series is the first to report a case of primary cutaneous peripheral T-cell lymphoma of the penis, confirmed by immunohistochemical stains. Rare cases of urethral lymphomas in men have also been described. ${ }^{36,37}$

Ureteral lymphomas are also very rare with only a few case reports. ${ }^{38,39}$ Patients typically present with obstructive symptomatology and may subsequently develop unilateral hydronephrosis. Though most cases are unilateral, a case of primary bilateral ureteral lymphoma has been described. ${ }^{39}$

Although this study is limited by the fact that it is an institutional study, the diversity of lymphoma subtypes and sites of involvement in this group of cases underscores the importance of considering lymphoma or plasmacytoma in the differential diagnosis of tumors of the urinary tract and male genital organs.

\section{Disclosure/conflict of interest}

The authors declare no disclosure or conflict of interest.

\section{References}

1 U.S. Cancer Statistics Working Group. United States Cancer Statistics: 1999-2004 Incidence and Mortality Web-based Report. U.S. Department of Health and Human Services, Centers for Disease Control and Prevention and National Cancer Institute: Atlanta, 2007. Available at:www.cdc.gov/uscs.

2 Krol ADG, le Cessie S, Snijder S, et al. Primary extranodal non-Hodgkin's lymphoma (NHL): the impact of alternative definitions tested in the Comprehensive Cancer Centre West population-based NHL registry. Ann Oncol 2003;14:131-139.

3 Al-Abbadi MA, Hattab EM, Tarawneh M, et al. Primary testicular and paratesticular lymphoma: a retrospective clinicopathologic study of 34 cases with emphasis on differential diagnosis. Arch Pathol Lab Med 2007;131:1040-1046.

4 Bates AW, Norton AJ, Baithun SI. Malignant lymphoma of the urinary bladder: a clinicopathological study of 11 cases. J Clin Pathol 2000;53:458-461.

5 Bostwick DG, Iczkowski KA, Amin MB, et al. Malignant lymphoma involving the prostate: report of 62 cases. Cancer 1998;83:732-738.

6 Ferry JA, Harris NL, Papanicolaou N, et al. Lymphoma of the kidney. A report of 11 cases. Am J Surg Pathol 1995;19:134-144.

7 Ferry JA, Harris NL, Young RH, et al. Malignant lymphoma of the testis, epididymis, and spermatic cord. A clinicopathologic study of 69 cases with immunophenotypic analysis. Am J Surg Pathol 1994;18:376-390.

8 Taheri MR, Dighe MK, Kolokythas O, et al. Multifaceted genitourinary lymphoma. Curr Probl Diagn Radiol 2008;37:80-93.

9 Cupisti A, Riccioni R, Carulli G, et al. Bilateral primary renal lymphoma treated by surgery and chemotherapy. Nephrol Dial Transplant 2004;19:1629-1633.

10 Tefekli A, Baykal M, Binbay M, et al. Lymphoma of the kidney: primary or initial manifestation of rapidly progressive systemic disease? Int Urol Nephrol 2006;38:775-778.

11 Arranz Arija JA, Carrion JR, Garcia FR, et al. Primary renal lymphoma: report of 3 cases and review of the literature. Am J Nephrol 1994;14:148-153.

12 Hunter S, Samir A, Eisner B, et al. Diagnosis of renal lymphoma by percutaneous image guided biopsy: experience with 11 cases. J Urol 2006;176:1952-1956.

13 Törnroth T, Heiro M, Marcussen N, et al. Lymphomas diagnosed by percutaneous kidney biopsy. Am J Kidney Dis 2003;42:960-971.

14 Sheth S, Ali S, Fishman E. Imaging of renal lymphoma: patterns of disease with pathologic correlation. Radiographics 2006;26:1151-1168.

15 Garcia M, Konoplev S, Morosan C, et al. MALT lymphoma involving the kidney: a report of 10 cases and review of the literature. Am J Clin Pathol 2007;128:464-473.

16 Tuzel E, Mungan MU, Yorukoglu K, et al. Primary renal lymphomaof mucosa-associated lymphoid tissue. Urology 2003;61:463.

17 Verma N, Lazarchick J, Gudena V, et al. Testicular lymphoma: an update for clinicians. Am J Med Sci 2008;336:336-341.

18 Al-Abbadi MA, Hattab EM, Tarawneh MS, et al. Primary testicular diffuse large B-cell lymphoma belongs to the nongerminal center B-cell-like subgroup: a study of 18 cases. Mod Pathol 2006;19: 1521-1527.

19 Park BB, Kim JG, Sohn SK, et al. Consideration of aggressive therapeutic strategies for primary testicular lymphoma. Am J Hematol 2007;82:840-845.

20 Vitolo U, Ferreri AJ, Zucca E. Primary testicular lymphoma. Crit Rev Oncol Hematol 2008;65: 183-189.

21 Chim CS, Loong F, Yau T, et al. Common malignancies with uncommon sites of presentation: case 2. Mantlecell lymphoma of the prostate. J Clin Oncol 2003;21: 4456-4458.

22 Jhavar S, Agarwal JP, Naresh KN, et al. Primary extranodal mucosa associated lymphoid tissue (MALT) lymphoma of the prostate. Leuk Lymphoma 2001;41: $445-449$. 
23 Choi WW, Yap RL, Ozer O, et al. Lymphoma of the prostate and bladder presenting as acute urinary obstruction. J Urol 2003;169:1082-1083.

24 Singh I, Joshi M, Agarwal S, et al. Extra-nodal small cell lymphocytic lymphoma of prostate: an unusual cause of lower urinary tract symptoms. Urology 2008;71:547.e7-547.e9.

25 Bouet R, Thwaites D, Harris SB, et al. Asymptomatic follicular lymphoma of the prostate discovered by abnormal digital rectal examination. J Urol 2004;171: 795-796.

26 Mermershtain W, Benharroch D, Lavrenkov K, et al. Primary malignant lymphoma of the prostate-a report of three cases. Leuk Lymphoma 2001;42:809-811.

27 Fernández Aceñero MJ, Martín Rodilla C, López García-Asenjo J, et al. Primary malignant lymphoma of the bladder. Report of three cases. Pathol Res Pract 1996;192:160-165.

28 Hughes M, Morrison A, Jackson R. Primary bladder lymphoma: management and outcome of 12 patients with a review of the literature. Leuk Lymphoma 2005;46:873-877.

29 Kempton CL, Kurtin PJ, Inwards DJ, et al. Malignant lymphoma of the bladder: evidence from 36 cases that low-grade lymphoma of the MALT-type is the most common primary bladder lymphoma. Am J Surg Pathol 1997;21:1324-1333.

30 Al-Maghrabi J, Kamel-Reid S, Jewett M, et al. Primary low-grade B-cell lymphoma of mucosa-associated lymphoid tissue type arising in the urinary bladder: report of 4 cases with molecular genetic analysis. Arch Pathol Lab Med 2001;125:332-336.
31 Cohen DD, Lamarre C, Lamarre L. Primary low-grade B-cell lymphoma of the urinary bladder: case report and literature review. Can J Urol 2002;9:1694-1697.

32 Wazait HD, Chahal R, Sundurum SK, et al. MALT-type primary lymphoma of the urinary bladder: clinicopathological study of 2 cases and review of the literature. Urol Int 2001;66:220-224.

33 Kim HY, Oh SY, Lee S, et al. Primary penile diffuse large B cell lymphoma treated by local excision followed by rituximab-containing chemotherapy. Acta Haematol 2008;120:150-152.

34 Lo HC, Yu DS, Lee CT, et al. Primary B cell lymphoma of the penis: successful treatment with organ preservation. Arch Androl 2003;49:467-470.

35 Wei CC, Peng CT, Chiang IP, et al. Primary B cell nonHodgkin lymphoma of the penis in a child. J Pediatr Hematol Oncol 2006;28:479-480.

36 Masuda A, Tsujii T, Kojima M, et al. Primary mucosa-associated lymphoid tissue (MALT) lymphoma arising from the male urethra. A case report and review of the literature. Pathol Res Pract 2002;198: $571-575$.

37 Richter LA, Hegde P, Taylor III JA. Primary nonHodgkin's B-cell lymphoma of the male urethra presenting as stricture disease. Urology 2007;70: 1008.e11-1008.e12.

38 Hashimoto $\mathrm{H}$, Tsugawa M, Nasu Y, et al. Primary non-Hodgkin lymphoma of the ureter. BJU Int 1999;83: 148-149.

39 Kubota Y, Kawai A, Tsuchiya T, et al. Bilateral primary malignant lymphoma of the ureter. Int J Clin Oncol 2007;12:482-484. 